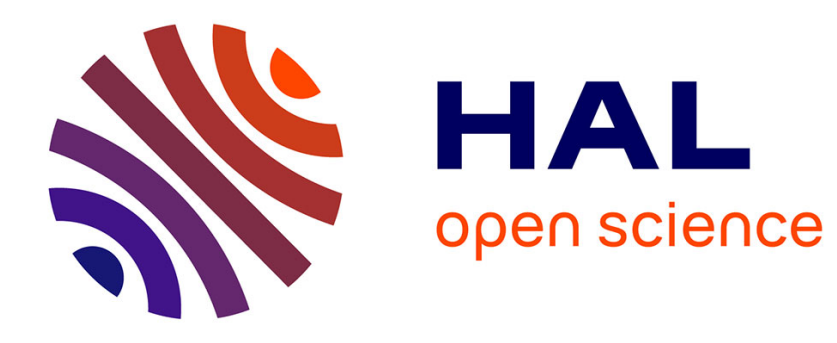

\title{
Internal Friction and Elastic Constants of Sintered Titanium
}

\author{
H. Ledbetter, M. Dunn, S. Kim
}

\section{To cite this version:}

H. Ledbetter, M. Dunn, S. Kim. Internal Friction and Elastic Constants of Sintered Titanium. Journal de Physique IV Proceedings, 1996, 06 (C8), pp.C8-859-C8-862. 10.1051/jp4:19968185 jpa-00254622

\section{HAL Id: jpa-00254622 https://hal.science/jpa-00254622}

Submitted on 1 Jan 1996

HAL is a multi-disciplinary open access archive for the deposit and dissemination of scientific research documents, whether they are published or not. The documents may come from teaching and research institutions in France or abroad, or from public or private research centers.
L'archive ouverte pluridisciplinaire HAL, est destinée au dépôt et à la diffusion de documents scientifiques de niveau recherche, publiés ou non, émanant des établissements d'enseignement et de recherche français ou étrangers, des laboratoires publics ou privés. 


\title{
Internal Friction and Elastic Constants of Sintered Titanium
}

\author{
H. Ledbetter, M. Dunn* and S. Kim \\ Materials Science and Engineering Laboratory, National Institute of Standards and Technology, Boulder, \\ Colorado 80303, U.S.A. \\ * Center for Acoustics, Mechanics, and Materials, Mechanical Engineering Department, University of \\ Colorado, Boulder, Colorado 80309, U.S.A.
}

\begin{abstract}
Using a Marx-oscillator standing-wave resonancemethod, we measured the internal friction $Q^{-1}$ of sintered titanium containing up to 26 volume-percent voids $(c)$. The surprising $Q^{-1}$-versus- $c$ curve shape, an exponential increase, lead us to remeasure $Q^{-1}$-versus- $c$ by acoustic-resonance spectroscopy, which gave similar results. We hypothesized that both void shape and void size change with $c$. For the void shape, we confirmed this hypothesis by measuring longitundinal and transverse sound velocities $v_{l}$ and $v_{t}$ and comparing them with Mori-Tanaka model predictions. As $c$ increases from 0 to 0.26 , effective void shape changes from near spherical to oblate spheroidal with an aspect ratio near 0.05 . Optical microscopy confirmed the void-size change. We outline a model based on wavescattering theory that explains the observed $Q^{-1}-c$ behavior. Increased particle size with increased $c$ provides the dominant factor for the exponential $Q^{-1}$ increase.
\end{abstract}

\section{INTRODUCTION}

Elastic-stiffness constants and their imaginary part, the internal friction $Q^{-1}$, provide much valuable information about a material's microstructure, about all defects representing departures from an ideal, pure, perfect monocrystal. The defect considered here is voids arising from sintering of spherical particles. At least at low void concentrations, we expect the voids to possess simple shapes, approaching in many cases the concave-face tetrahedron associated with the interstices of close-packed spheres.

\section{MATERIAL}

As a specimen material, we chose sintered titanium. Chemically pure titanium powder was prepared by a rotating-anode method, sieved through -35 mesh to give an average $180-\mu \mathrm{m}$ particle size, sealed in titanium canisters, and hot isostatically pressed to various mass densities, which were determined by pressure and temperature.

\section{MEASUREMENT METHODS}

In this study, we used five measurement methods:

1. Marx-oscillator [1]. In the extensional mode, this gave the Young modulus $E$ and the associated internal friction $Q^{-1}$.

2. Acoustic-resonance-spectroscopy [2]. For a near- $C_{44}$ mode, this confirmed the $Q^{-1}$ measurement made by method 1 . In Table 1 , we label this $Q_{G}^{-1}$.

3. Rod-resonance [3]. This confirmed the $E$ and $Q^{-1}$ measurements made by method 1 .

4. Pulse-echo-superposition [4]. This gave the complete set of elastic constants. Because of large bond and transducer corrections, we ignored the accompanying attenuation measurements, which give $Q^{-1}$. 
5. Impulse-excitation rod-resonance [5]. By exciting extensional, bending, and torsional modes of a rectangular bar, this gave the elastic constants of a $c=0.39$ specimen, which resisted accurate measurement by the above four methods. The accompanying $Q^{-1}$ measurement was too inaccurate.

\section{RESULTS}

Figure 1 shows the change of $Q^{-1}$ with $c$, the void volume fraction, obtained from Archimedes-method mass-density measurements. Table 1 gives numerical values for mass density, sound velocities, various polycrystalline (quasi-isotropic) elastic constants, and internal friction. In this table, $\rho$ denotes mass density, $v_{l}$ and $v_{t}$ longitudinal and transverse sound velocities, $C_{l}$ longitudinal modulus, $G$ shear modulus, $B$ bulk modulus, $E$ Young modulus, $v$ Poisson ratio, and $Q^{-1}$ internal friction, where subscript $E$ denotes Young-modulus (extensional) mode and subscript $G$ shear mode.

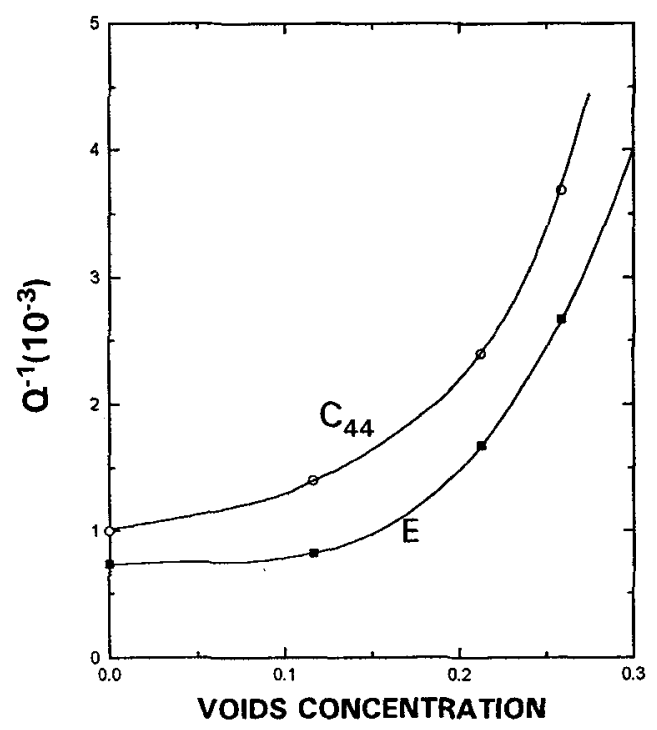

Figure 1: Dependence of internal friction $Q^{-1}$ on void concentration. The upper curve corresponds to $C_{44}$ transversemodulus mode from acoustic-resonance spectroscopy. The lower curve corresponds to Young-modulus $E$ mode from Marx-oscillator standing-wave resonance. For an isotropic material, $C_{44}$ equals the shear modulus $G$.

Table 1. Measured elastic constants and internal friction

\begin{tabular}{|c|c|c|c|c|c|c|c|c|c|c|}
\hline $\begin{array}{l}\text { Void con- } \\
\text { tent }(\%)\end{array}$ & $\stackrel{\rho}{\left(\mathrm{g} / \mathrm{cm}^{3}\right)}$ & $\begin{array}{c}v_{l} \\
(\mathrm{~cm} / \mu \mathrm{s})\end{array}$ & $\begin{array}{c}v_{t} \\
(\mathrm{~cm} / \mu \mathrm{s})\end{array}$ & $\begin{array}{c}C_{l} \\
(\mathrm{GPa})\end{array}$ & $\begin{array}{c}G \\
(\mathrm{GPa})\end{array}$ & $\begin{array}{c}B \\
(\mathrm{GPa})\end{array}$ & $\begin{array}{c}E \\
(\mathrm{GPa})\end{array}$ & $v$ & $\begin{array}{c}\mathrm{Q}_{E}^{-1} \\
\left(10^{-3}\right)\end{array}$ & $\begin{array}{c}Q_{G}^{-1} \\
\left(10^{-3}\right)\end{array}$ \\
\hline $0^{*}$ & 4.421 & 0.6061 & 0.3157 & 162.4 & 44.06 & 103.7 & 115.77 & 0.3139 & $0.730^{\dagger}$ & $0.996^{\S}$ \\
\hline $11.7^{*}$ & 3.968 & 0.4532 & 0.2609 & 81.49 & 27.01 & 45.47 & $\begin{array}{l}67.639 \\
67.516^{\dagger} \\
67.563^{\ddagger}\end{array}$ & 0.2521 & $0.816^{\dagger}$ & $1.395^{\S}$ \\
\hline $21.3^{*}$ & 3.626 & 0.3529 & 0.2168 & 45.16 & 17.04 & 22.44 & $\begin{array}{l}40.792 \\
42.120^{\dagger} \\
42.501^{\dagger}\end{array}$ & 0.1971 & $1.672^{\dagger}$ & $2.390^{\S}$ \\
\hline $25.9^{*}$ & 3.417 & 0.2955 & 0.1954 & 29.84 & 13.05 & 12.44 & $\begin{array}{l}29.007 \\
29.827^{\dagger} \\
28.583^{\dagger}\end{array}$ & 0.1113 & $2.664^{\dagger}$ & $3.675^{\S}$ \\
\hline $38.6^{\mathrm{z}}$ & 2.763 & 0.1147 & 0.0755 & 3.634 & 1.577 & 1.531 & 3.522 & 0.117 & & \\
\hline
\end{tabular}




\section{MODELING OF ELASTIC CONSTANTS}

Many models exist for predicting a composite's effective sound velocities and elastic constants from constituent properties and phase geometry [6].

For this study, we used the Mori-Tanaka effective-field approach [7] to obtain explicit analytical expressions for the effective long-wavelength-limit longitudinal-wave and transverse-wave sound velocities of porous solids. This approach offers the advantages of yielding, for undilute concentrations, explicit analytical expressions, not simply bounds or estimates that require iterative calculations. The solid's effective elastic properties are estimated by assuming that a representative inclusion (void) feels the effect of the average matrix stress in the same way that an isolated inclusion feels an applied uniform stress. Thus, the inclusion feels an effective field.

From the Mori-Tanaka model, we obtained explicit longitudinal and transverse sound-velocity $\left(v_{l}\right.$ and $v_{t}$ ) expressions for several possible void shapes. For brevity, we give only the following results for randomly oriented spheroidal pores:

$$
\begin{aligned}
& \frac{v_{l}}{v_{l_{0}}}=\left[\frac{3(1-c)\left(1-\nu_{0}\right)+2 c f\left(\nu_{0}, \alpha\right)\left(1-2 \nu_{0}\right)+c h\left(\nu_{0}, \alpha\right)\left(1+\nu_{0}\right)}{3\left(1-\nu_{0}\right)\left[1-c\left\{1-f\left(\nu_{0}, \alpha\right)\right\}\right]\left[1-c\left\{1-h\left(\nu_{0}, \alpha\right)\right\}\right]}\right]^{1 / 2} ; \\
& \frac{v_{t}}{v_{l o}}=\left[\frac{1}{1-c\left\{1-h\left(\nu_{0}, \alpha\right)\right\}}\right]^{1 / 2} .
\end{aligned}
$$

Here, $v_{l}=$ longitudinal velocity of the porous solid; $v_{t}=$ transverse velocity of the porous solid; $v_{l_{0}}$ $=$ longitudinal velocity of the bulk solid; $v_{t_{0}}=$ transverse velocity of the bulk solid; $v_{0}=$ Poisson ratio of the bulk solid; $\alpha=$ pore aspect ratio; $c=$ pore concentration;

$$
\begin{aligned}
& f\left(\nu_{0}, \alpha\right)=\frac{1-\nu_{0}}{6\left(1-2 \nu_{0}\right)} \frac{4\left(1+\nu_{0}\right)+2 \alpha^{2}\left(7-2 \nu_{0}\right)+\left[3\left(1-4 \nu_{0}\right)-12 \alpha^{2}\left(2-\nu_{0}\right)\right] g(\alpha)}{2 \alpha^{2}+\left(1-4 \alpha^{2}\right) g(\alpha)+\left(\alpha^{2}-1\right)\left(1+\nu_{0}\right) g(\alpha)^{2}} ; \\
& h\left(\nu_{0}, \alpha\right)=\frac{4\left(1-\nu_{0}\right)\left(\alpha^{2}-1\right)}{15}\left\{\frac{6}{\alpha^{2}-4\left(1-\nu_{0}\right)\left(\alpha^{2}-1\right)+\left[2\left(1-2 \nu_{0}\right)\left(\alpha^{2}-1\right)-3 / 2\right] g(\alpha)}\right. \\
& -\frac{6}{4 a^{2}+\left[\left(1-2 \nu_{0}\right)\left(\alpha^{2}-1\right)-3\left(\alpha^{2}+1\right)\right] g(\alpha)} \\
& \left.-\frac{1}{2 \alpha^{2}+\left[\left(1-4 \alpha^{2}\right)\right] g(\alpha)+\left[\left(1+\nu_{0}\right)\left(\alpha^{2}-1\right)\right] g(\alpha)^{2}}\right\} \text {; }
\end{aligned}
$$

and

$$
\begin{aligned}
g(\alpha) & =\frac{\alpha}{\left(\alpha^{2}-1\right)^{3 / 2}}\left\{\alpha\left(\alpha^{2}-1\right)^{1 / 2}-\cosh ^{-1} \alpha\right\} \text { for } \alpha>1 \\
& =\frac{\alpha}{\left(1-\alpha^{2}\right)^{3 / 2}}\left\{\cos ^{-1} \alpha-\alpha\left(1-\alpha^{2}\right)^{1 / 2}\right\} \quad \text { for } \alpha^{<<1} \\
& =2 / 3 \quad \text { for } \alpha=1 .
\end{aligned}
$$




\section{DISCUSSION}

Previously, we described the expected dependence of $Q^{-1}$ on $c$, derived from a scattered-plane-wave ensemble-average model and applied to $\mathrm{SiC}$ particles in an $\mathrm{Al}$ matrix [8]. For fixed particle size and shape, $Q^{-1}$ increases linearly, decreases in slope, and passes through a broad maximum. For a fixed shape and concentration, $Q^{-1}$ strongly increases nonlinearly with increasing particle size. Thus, as void size increases with increasing $c, Q^{-1}$ can increase exponentially. Our previous study [8] showed that decreasing particleshape aspect ratio (spherical to oblate spheroidal) decreases $Q^{-1}$; thus, a $Q^{-1}-c$ curve dominated by the shape factor would be convex rather than concave. Our measurement results show that the size change more than compensates for the shape change.

\section{CONCLUSIONS}

In studying the internal friction and elastic constants of sintered titanium, we reached five principal conclusions:

1. Against expectation, internal friction $Q^{-1}$ increases exponentially with increasing void content.

2. Elastic-constant measurements combined with the Mori-Tanaka theory show that the effective void aspect ratio decreases with increasing $c$, that is, from spherical to strongly oblate spheroidal $(\alpha \simeq 0.05)$.

3. The unexpected $Q^{-1}-c$ curve can be explained by invoking increased void size, supported by optical microscopy and using a model developed previously for particle-reinforced composites. The model considers plane waves scattered from a particle ensemble.

4. Change in void shape causes an opposite and smaller effect on $Q^{-1}$ than does void size.

5. Internal friction provides a valuable probe of these materials because it depends strongly on void size, which produces no effect on the elastic stiffnesses.

\section{References}

[1] Ledbetter, H., Cryogenics 20 (1980) 637.

[2] Ledbetter, H., Fortunko, C., and Heyliger, P. J. Appl. Phys. 78 (1995) 1542.

[3] Pollard, H., Sound Waves in Solids (Pion, London, 1977) pp. 147-157.

[4] Ledbetter, H., Frederick, N., and Austin, M., J. Appl. Phys. 51 (1980) 305.

[5] Lemmens, J., in Dynamic Elastic Modulus Measurements in Materials (ASTM, Philadlephia, 1990) pp. 90-99.

[6] Watt, J., Davies, G., and O'Connell, R., Rev. Geophys. Space Phys. 14 (1976) 541.

[7] Mori, T. and Tanaka, K., Acta Metall. 21 (1973) 571.

[8] Ledbetter, H., Datta, S., Kriz, R., and Austin, M., "Physical-property modeling in silicon-carbide/aluminum," Disc. Reinf. Alum. Compos., Jan. 1984 (DoD MMClAC, Santa Barbara, California, 1984) pp. 67-94.

U.S.-government contribution; not subject to copyright. 